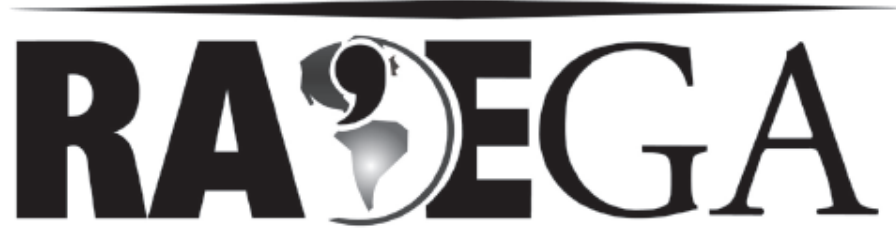

O ESPAÇO GEOGRÁFICO EM ANÁLISE

\title{
SAZONALIDADE DO TURISMO NO MUNICÍPIO DE GUARATUBA, PARANÁ, BRASIL
}

TOURISM SEASONALITY IN GUARATUBA, PARANÁ, BRAZIL

\author{
Luciane SCHEUER $^{1}$
}

Miguel $\mathrm{BAHL}^{2}$

\section{RESUMO}

A crescente importância que o turismo tem assumido em termos globais e particularmente no quadro de algumas economias ocidentais justifica a preocupação dos setores público e privado em obter um conhecimento mais aprofundado sobre os efeitos do fenômeno turístico. Dentre eles surge a sazonalidade que é algo muito complexo e que a partir do seu estudo tem-se como identificar seus impactos, seus problemas e racionalizar soluções cabíveis em cada situação ou comunidade receptora. O presente estudo buscou comprovar e caracterizar a existência da sazonalidade turística no município de Guaratuba, Paraná, Brasil, por meio da abordagem de conceitos relacionados ao turismo e à geografia do turismo e voltá-los para o estudo do turismo sazonal. Empiricamente, esta pesquisa caracterizou o objeto de estudo, ou seja, Guaratuba e questionou 11 pessoas envolvidas direta e indiretamente com turismo no município, utilizando entrevista focalizada para posterior análise e comprovação do fenômeno, suas causas e seus efeitos.

Palavras-chave: Turismo; Guaratuba; causas; efeitos; sazonalidade.

\footnotetext{
1 Graduação em Comunicação Social pela Pontifícia Universidade Católica do Paraná e em Turismo pela Universidade Federal do Paraná. Pós-graduação em Planejamento turístico (UFPR) e Gestão Empresarial (Fac. Mater Dei). Doutoranda em Geografia pela Universidade Federal do Paraná. Mestre em Geografia (UFPR). Professora do curso de Turismo no Instituto Superior do Litoral do Paraná (ISULPAR - Paranaguá). luscheuer@hotmail.com

${ }^{2}$ Graduação em Estudos Sociais, em Geografia e em Turismo pela Universidade Federal do Paraná, mestrado e doutorado em Ciências da Comunicação pela Universidade de São Paulo. Professor Titular do Departamento de Turismo da Universidade Federal do Paraná. migbahl@ufpr.br
} 


\section{ABSTRACT}

The increasing importance that tourism has been taking over in global terms and particularly in some western economies, justifies the great attention given from public and private sectors, about a deeper knowledge of the tourist phenomenon. And inside this phenomenon arises the seasonality that is something very complex and its study can identify its impacts, its problems and to rationalize founded solutions in each situation or receiver community. The present study sought to characterize and to prove the existence of the tourist seasonality in Guaratuba, Paraná, Brazil, through the concepts approach related to tourism and tourism geography and turn them to the study of the seasonal tourism. Empirically this research characterized the study object, in other words, Guaratuba, and it questioned 11 direct and indirectly involved people to the tourism in the city, using focalized interview for posterior analysis and confirmation of the phenomenon, its causes and effects.

Key-words: Tourism; Guaratuba; causes; effects; seasonality.

\section{INTRODUÇÃO}

Construir uma pesquisa sobre o turismo do município de Guaratuba, que sofre anualmente com os impactos decorrentes da sazonalidade e da falta de um planejamento turístico mais efetivo, é um tanto quanto instigante. Isso, pois a cidade de Guaratuba está inserida numa das regiões de maior diversidade paisagística do litoral do estado do Paraná (Brasil) e com um contexto histórico, econômico e cultural singular. Uma cidade que vivencia cotidianamente os anseios de uma parte da comunidade que a quer desenvolvida e bonita, e as dificuldades daqueles que a constroem e a administram, num conflito constante que se espacializa, formando, ao longo do tempo, territórios e territorialidades difíceis de serem compreendidos.

Para tanto, neste artigo, se apresentam os resultados de uma pesquisa que buscou abordar os conceitos relacionados ao turismo e à geografia do turismo e voltá-los para o estudo do turismo sazonal, com a intenção de comprovar e caracterizar a existência da sazonalidade turística no município de Guaratuba e seus reflexos na comunidade local. Para Butler (1994, p. 332) turismo sazonal é um desequilíbrio temporal no fenômeno turístico, que pode ser expresso em termos de dimensões tais como: número de visitantes, despesas de visitantes, tráfego nas autoestradas e em outras formas de transporte, emprego e ingressos em atrações. 
Portanto, pode-se considerar que a sazonalidade é a concentração dos fluxos turísticos em períodos curtos do ano, promovendo, por um lado, picos nas atividades de prestação de serviços gerais e aos turistas, que muitas vezes, se constituem como um pesado fardo para os recursos físicos e sociais na área-destino e, por outro, épocas de pouca procura que geram ineficiência na atividade turística de um local ou região.

Localidades de veraneio, como é o caso de Guaratuba, necessitam de planejamento turístico contínuo, a fim de reverter a situação negativa, causada pela sazonalidade, fazendo com que o turismo possa ser explorado satisfatoriamente o ano todo. Conforme Almeida (2000), os prejuízos do turismo sazonal em muitas localidades são muito maiores do que o retorno que ele proporciona em épocas de temporada. Além disso, basta uma temporada ruim, com mau tempo, ou problemas na economia nacional, que um local demorará anos para se recompor economicamente.

A pesquisa foi realizada a partir de duas etapas: a primeira a partir de um estudo teórico sobre conceitos relacionados ao turismo, à geografia do turismo, à sazonalidade e de caracterização do objeto de pesquisa, ou seja, o município de Guaratuba e as suas peculiaridades, e a segunda ao empreender uma pesquisa de campo, na qual fosse possível comprovar e caracterizar a existência da sazonalidade no mesmo.

Pode-se afirmar que a atividade turística no município, encontra-se de forma consolidada, atraindo um grande número de turistas, principalmente nos meses em que ocorrem as férias de verão. A partir disso, questionou-se se a sazonalidade do turismo em Guaratuba acarretaria reflexos tanto na qualidade de prestação de serviços turísticos quanto na vida da comunidade em geral.

Este estudo foi dividido em tópicos teóricos, elaborados por meio de revisão da literatura referente ao turismo, à geografia do turismo, à sazonalidade e suas causas e de caracterização do município. Também foi feita uma abordagem sobre a metodologia de trabalho e a pesquisa de campo, realizada utilizando entrevista focalizada e observação assistemática, para posterior análise dos dados e apresentação das considerações finais.

Pode-se considerar que os resultados deste trabalho sejam de grande relevância para o desenvolvimento de outros estudos sobre turismo de modo geral e 
da geografia, pois este leva em consideração vários aspectos inerentes de ordem territorial, espacial, econômica, entre outros. Isso, tanto para as pessoas interessadas neste assunto e principalmente para o município de Guaratuba, que anualmente sofre com os efeitos decorrentes da sazonalidade. Evidencia-se dessa forma que lugares que convivem com a sazonalidade devem procurar desenvolver estratégias para minimizarem os efeitos das situações de altos e baixos fluxos turísticos.

\section{CONCEITOS SOBRE TURISMO}

Os seres humanos sempre se deslocaram no espaço por uma série de motivos, como a busca de alimentos ou de abrigo, o domínio dos territórios, a conquista de riquezas, além de fatores religiosos, culturais, sociais, entre outros. Entretanto, o deslocamento de pessoas conhecido como fenômeno turístico, que se constitui em prática social com características econômicas, começou a se desenvolver formalmente a partir do século XIX, mais precisamente após 1860. (BONFIM, 2007, p. 39).

Conforme Krippendorf (1989), a grande mobilidade tomou conta da maioria dos habitantes das nações industriais e assim, as pessoas aproveitam todas as oportunidades para viajar e para fugir do cotidiano, com a maior frequência possível. Para muitas pessoas não há desejo maior que o de viajar, mudar de endereço temporariamente e fugir da rotina, demonstrando o quanto é importante e complexo o estudo da atividade turística.

Ao longo das décadas, o turismo tem experimentado um crescimento contínuo e de aprofundamento da sua diversificação para se tornar um dos setores econômicos que mais se expandem em todo o mundo. O turismo moderno está intimamente ligado ao desenvolvimento e abrange um número crescente de novos destinos. Essa dinâmica tem transformado o turismo em uma espécie de "motor essencial" para o progresso socioeconômico de várias localidades.

A Organização Mundial do Turismo (OMT, 2001, p. 38) estipulou uma definição nos seguintes termos: "o turismo compreende as atividades realizadas pelas pessoas durante suas viagens e estadas em lugares diferentes do seu entorno 
habitual, por um período consecutivo inferior a um ano, por lazer, negócios ou outros".

Por ser um assunto complexo e em ampla expansão, há tantas definições, quanto autores, escrevendo sobre ele. Para Barretto (1991, p. 47-48), o turismo é essencialmente o movimento de pessoas e 0 atendimento às suas necessidades enquanto viajantes, assim como às necessidades das outras pessoas que moram nas localidades de destino dos turistas. O turismo é o fenômeno de interação entre o turista e o núcleo receptor e de todas as atividades decorrentes dessa interação.

Bahl (2004, p. 45), acrescenta que em sua essência, o turismo pode ser um promotor das localidades onde ocorre, obrigando a necessidade do resgate da cultura local, o estímulo à autoestima e valorização dos hábitos e costumes autóctones. A partir de tal colocação pode-se afirmar que a manutenção da autenticidade das localidades é um dos recursos mais promissores do turismo.

Ainda, conforme OMT (2001), o volume de negócios do turismo é igual ou até supera o das exportações de petróleo, produtos alimentares ou de automóveis. $O$ turismo tornou-se um dos principais vetores do comércio internacional e representa, ao mesmo tempo, uma das principais fontes de rendimentos para muitos países em desenvolvimento. Em virtude disso, esse crescimento ocasiona uma maior diversificação e concorrência entre os destinos.

Considerando-se todas as questões supracitadas, evidencia-se que a compreensão do significado do que possa ser considerado como turismo não pode se limitar apenas em defini-lo hermeticamente, pois este é um fenômeno que também é pesquisado em distintos campos de estudo de várias outras áreas de conhecimento, explicado, por vezes, conforme diferentes correntes de pensamento, e verificado em vários contextos da realidade social.

\section{GEOGRAFIA DO TURISMO}

Pode-se mencionar que o turismo é, em essência, uma prática social. Uma prática social, agregada ao mercado, que tem no espaço seu principal objeto de consumo e, em decorrência dessa característica intrínseca, requer a adaptação dos territórios as suas demandas materiais e imateriais. Conforme Crocia (2002, p. 9), o turismo se expande, usualmente, por áreas onde já existiam assentamentos 
humanos. Isto quer dizer que quando a difusão da função turística começa a acontecer em uma região inicia-se uma interação entre os componentes da função nova (o turismo) e os componentes da região receptora.

Pode-se afirmar, inclusive, que as qualidades naturais e culturais prévias apresentadas por uma região ou de uma localidade acabam mesmo por influenciar, e não raro de forma decisiva, as próprias decisões dos agentes privados e públicos de nelas investir no turismo.

Mitchell e Murphy (1991) definem como objeto de estudo da Geografia do Turismo as inter-relações que se criam entre os turistas, a população local e as atividades realizadas, tendo-se como referência o espaço. Nesse contexto, os estudos pertinentes à Geografia do Turismo abordariam aspectos ambientais, regionais e evolutivos do espaço. De acordo com Boniface e Cooper (1994), o objeto de estudo da Geografia do Turismo é a expressão espacial do turismo como atividade humana, centrada tanto na área de origem quanto na de destino assim como na relação entre ambas.

Pearce (1988) indica seis áreas que constituem a Geografia do Turismo: a) os padrões de distribuição espacial da oferta; b) os padrões de distribuição espacial da demanda; c) a geografia dos centros de férias; d) os movimentos e os fluxos turísticos; e) o impacto do turismo; e f) os modelos de desenvolvimento do espaço turístico.

Ou seja, pode-se estipular que o estudo do desenvolvimento turístico abrange todas essas áreas, priorizando as questões referentes à oferta, à localização e aos impactos decorrentes. Ivars (2002, p. 19) menciona a existência de duas linhas de trabalho que contemplam o objeto de estudo da Geografia do Turismo, a perspectiva de análise espacial em sua dimensão aplicada, muito evoluída a respeito das formulações tradicionais, e os enfoques mais reflexivos e críticos, que ampliam e atualizam o corpo teórico da Geografia do Turismo.

Embora as linhas sejam diferenciadas, elas não são contraditórias e são, sem dúvida, de interesse para o planejamento turístico. No Brasil, de acordo com Rejowski (1996), o estudo do Turismo vem evoluindo com esforços em pesquisa e ensino de forma semelhante ao processo de cientificidade já ocorrido em outras áreas das ciências humanas e sociais, delineando-se parâmetros com seus componentes e dimensões característicos para o Turismo. 
Bonfim (2007, p. 45) menciona que, por meio de pesquisas realizadas, constatou-se grande dificuldade de adequação formal da inserção do Turismo e de seus conteúdos às necessidades de um curso de Geografia, bem como a ausência de um referencial teórico-metodológico que indique o melhor caminho para essa adequação. Isso ocorre porque os paradigmas da Geografia do Turismo foram se modificando com o tempo, e a evolução do campo de análise está tomando um rumo que mostra a existência de diferentes enfoques.

Bonfim (2007, p. 52) parte das premissas de que: a) a Geografia, enquanto ciência, pesquisa, analisa, interpreta e sintetiza o modo como os seres humanos, ao longo de sua existência, vêm ocupando, utilizando e transformando a natureza e também organizando o espaço de acordo com suas necessidades e seus desejos; e b) o Turismo implica o consumo, a produção e transformação dos objetos naturais em sociais.

Conclui-se, portanto, que a realidade do espaço turístico só pode ser entendida pelo conhecimento e compreensão de determinados conceitos geográficos. Consequentemente, a Geografia do Turismo surge como uma forma de estudar os territórios, os lugares, os espaços, dentre outros aspectos, onde acontece o fenômeno turístico e uma nova dinâmica social e sem dúvida os novos comportamentos turísticos.

\section{SAZONALIDADE}

A sazonalidade, em seu sentido contextual, pode ser definida como um determinado período de tempo para a ocorrência de um fenômeno, ou seja, conforme Mota (2001, p. 98) aquele que ocorre em alguns períodos e em outros não. Para Ruschmann (1995), a sazonalidade turística é decorrente da concentração das atividades turísticas no espaço e no tempo.

Muitos fatores podem condicionar a demanda turística, segundo Dencker (1998), estes podem ser: fatores demográficos, fatores sociológicos, fatores econômicos, fatores turísticos e a sazonalidade. Por sua vez, na sazonalidade da demanda turística devem-se levar em conta as seguintes variáveis: férias escolares ou dos trabalhadores, poder aquisitivo e concentração espaço-temporal das pessoas. (MOTA, 2001). 
Independentemente da variável, a ocorrência da sazonalidade turística, ainda conforme Mota (2001, p. 98) produz consequências em diversos níveis: gera desemprego, mortalidade em microempresas, queda no faturamento de empresas turísticas, alteração no sistema de gestão, compromete a qualidade no atendimento, modifica a política promocional do produto turístico, altera preços, exige maior flexibilidade administrativa, dentre outras.

A sazonalidade é algo muito mais complexo e a partir do seu estudo tem-se como identificar seus impactos, seus problemas e racionalizar soluções cabíveis em cada situação ou comunidade receptora.

Pode-se dizer que o clima e a localização geográfica influenciam a demanda turística de determinada região, e por causa, principalmente desses fatores, sofre a influência da sazonalidade.

Mas fatores climáticos e geográficos não devem ser vistos como os únicos responsáveis pela sazonalidade. O fenômeno pode ser desencadeado também por vários outros fatores advindos de várias razões, tanto referentes aos núcleos receptores quanto aos núcleos emissores.

Em particular, a concentração temporal ou sazonalidade, conforme Almeida e Kastenholz (2008, p. 2), é geralmente reconhecida na literatura como um fenômeno de caráter predominantemente econômico uma vez que é, consensualmente, relacionada com a adversidade das suas consequências neste plano, quer para as áreas de destino, quer para as empresas que nelas operam.

Os efeitos negativos da sazonalidade que passam, sobretudo pela ineficiência produtiva e por uma substantiva limitação de receitas do setor em nível anual, fazem com que este fenômeno seja encarado por parte das entidades gestoras das áreas de destino, como uma debilidade ou um problema maior a resolver.

Embora a sazonalidade da procura turística seja um fenômeno amplamente estudado, alguns autores caracterizam-no como pobremente compreendido, pelo menos, em algumas das suas facetas (BUTLER, 1994). Como referido anteriormente, pode-se dizer que a sazonalidade é aceita como um problema turístico global. O fenômeno afeta a maioria dos destinos turísticos, mas em particular aqueles que mais se distanciam da linha Equatorial, assim como, os mais periféricos em geral, pelo que, sobretudo nestas áreas, a sazonalidade tem sido um dos alvos privilegiados de políticas públicas e medidas de gestão privada visando a 
sua redução e a atenuação dos seus efeitos. (ALMEIDA; KASTENHOLZ, 2008). Contudo, a evidente persistência do problema leva a crer que uma parte substancial dessas políticas e medidas não atinge os seus objetivos, o que eventualmente reforça o argumento do ainda escasso entendimento sobre o fenômeno e, particularmente, sobre as suas causas. Parece, em essência, tratar-se de uma incapacidade expressa para compreender e atingir o âmago do problema. Será então conveniente explorar de forma detalhada a estrutura sazonal da procura existente numa área de destino, passando por uma análise do perfil dos turistas em diferentes épocas do ano (características e motivações), e, sobretudo, as causas que lhes estão associadas, para que se possam desenhar as estratégias mais adequadas e eficazes para enfrentar a sazonalidade?

Mais recentemente, a definição talvez mais referenciada seja a de Butler (1994) que apresenta a sazonalidade como um desequilíbrio temporal no fenômeno turístico, que pode ser expresso em termos de dimensões tais como: número de visitantes, despesas de visitantes, tráfego nas autoestradas e outras formas de transporte, emprego e ingressos em atrações. Outras definições destacam a concentração dos fluxos turísticos em períodos curtos do ano, promovendo, por um lado, picos de atividade que, muitas vezes, se constituem como uma sobrecarga para os recursos físicos e sociais nas áreas de destino e, por outro, situações de grande procura que geram ineficiência na atividade turística. (LAGE; MILONE, 2000).

Enfim, diversos são os agentes e grupos de interesse que participam e afetam o turismo de um país e consequentemente o fluxo de pessoas nas diferentes épocas do ano. A incorporação de perspectivas, de objetivos e esforços conjugados é vital para a elaboração do planejamento e para o desenvolvimento de um turismo cada vez menos sazonal.

Conforme Lage e Milone (1998, p. 61), a existência da sazonalidade da demanda turística, de curto prazo por temporada, prejudica a oferta turística, o que se torna um problema sério para o desenvolvimento da atividade. 


\section{CAUSAS DA SAZONALIDADE}

As dificuldades na identificação e estruturação mais aprofundada das causas da sazonalidade parecem resultar, em primeiro lugar, da grande complexidade atribuída ao fenômeno e, em segundo, a uma forte e intrincada correlação entre elas. A este propósito, Butler (2001) defende que o fenômeno carece de um aprofundamento de pesquisa em nível da identificação detalhada das suas causas mais contundentes, particularmente aquelas que se relacionam com as motivações de visita e padrões de consumo dos turistas.

Pode-se estabelecer que os fatores explicativos da concentração da procura turística variam de destino para destino, de acordo, entre outros aspectos, com as suas localizações geográficas, as diferentes origens dos turistas e os elementos de atratividade de cada destino.

A estrutura de correlações entre os fatores provoca, igualmente, diversos efeitos nos diferentes destinos. Existem, no entanto, fatores comuns que podem justificar a sazonalidade na maioria das áreas de destino. Mota (2001) sugere a sazonalidade e a relação de causa e efeito. As causas, conforme a autora são as férias escolares; o tempo livre; os fatores mercadológicos (concorrência, moda, baixa segmentação de produtos), ambientais (guerras, situações políticas etc.), econômicas (câmbio, renda etc.) e estruturais (violência, epidemias etc.). Quanto aos efeitos divide-os em relação às épocas de alto fluxo e baixo fluxo turístico, quando há alto fluxo de turistas, sugere que ocorre um incentivo ao mercado informal, inflação no núcleo receptor, aumento da prostituição e da degradação do meio ambiente. Havendo baixo fluxo, afirma que há desemprego, queda do faturamento das empresas turísticas, que provoca o comprometimento da qualidade do atendimento e que o baixo fluxo gera alteração nas promoções e nos preços dos produtos turísticos.

A partir do que foi descrito, pode-se afirmar que Mota (2001), é uma das pesquisadoras que mais se aproximou da realidade brasileira em relação às causas e efeitos da sazonalidade. Conhecer as causas da sazonalidade pode auxiliar o planejador a focar o desenvolvimento do turismo em seu território, buscando esforços para reduzir as flutuações de temporada tanto quanto possível. Sabendo os efeitos dessa época sazonal torna-se importante não somente para o planejador, 
mas também para todas as empresas e organizações envolvidas no processo turístico concentrar esforços para tentar fazer com que a distribuição da demanda turística ocorra de forma mais homogênea e regular durante 0 ano.

Já alguns autores sugerem o agrupamento das causas da sazonalidade em categorias, como ilustrado, de forma sintética, no quadro 1 de Köenig-Lewis e Bischoff (2005).

QUADRO 1 - CLASSIFICAÇÃO DAS CAUSAS DA SAZONALIDADE NO TURISMO

\begin{tabular}{|l|l|}
\hline \multicolumn{1}{|c|}{ AUTOR } & \multicolumn{1}{|c|}{ CATEGORIAS DE CAUSAS DA SAZONALIDADE } \\
\hline Baron (1975) & $\begin{array}{l}\text { Sazonalidade natural, sazonalidade institucional, efeitos dos diversos } \\
\text { calendários, causas sociológicas e econômicas. }\end{array}$ \\
\hline Hartmann (1986) & Sazonalidade natural, sazonalidade institucional. \\
\hline Butler (1994) & $\begin{array}{l}\text { Sazonalidade natural, sazonalidade institucional, pressão social e } \\
\text { moda, estações desportivas, tradição e inércia. }\end{array}$ \\
\hline Butler e Mao (1996) & $\begin{array}{l}\text { Fatores físicos e socioculturais nas áreas turísticas de origem e } \\
\text { destino. }\end{array}$ \\
\hline Frechtling (2001) & $\begin{array}{l}\text { Clima, costumes sociais/ férias, costumes profissionais, efeitos dos } \\
\text { diversos calendários. }\end{array}$ \\
\hline Baum e Hagen (1999) & $\begin{array}{l}\text { Tal como Frechtling (2001), mas adicionando os constrangimentos } \\
\text { da oferta. }\end{array}$ \\
\hline
\end{tabular}

FONTE: KÖENIG-LEWIS, N. e BISCHOFF, E. (2005).

A partir do quadro relacionado acima, duas categorias parecem reunir maior consenso, sendo elas: a sazonalidade natural e a institucional. Existem, no entanto, outras causas importantes da sazonalidade, que se relacionam com aspectos motivacionais que poderiam ser agrupadas numa terceira classe à qual se sugeriria chamar de sazonalidade comportamental, relacionada com determinadas motivações e preferências dos turistas que moldam os seus comportamentos de consumo e influenciam a sazonalidade, conforme Almeida e Kastenholz (2008).

Um desses fatores, reportado por Osborne (1992) consiste nos hábitos e tradições que moldam determinadas atitudes de consumo turístico. $\mathrm{O}$ autor sugere que esta possa ser uma justificativa importante para a sazonalidade no turismo, embora não existam estudos suficientes que a comprovem. Este fator traduz-se pela manutenção do comportamento de consumo que, por inércia ou, até, por resistência 
à mudança, caracteriza os turistas que já não são afetados pelos condicionalismos do passado (por exemplo: férias profissionais). (ALMEIDA; KASTENHOLZ, 2008, p. 10). Embora a calendarização do período para o gozo de férias possa ser uma das principais concretizações deste comportamento de consumo, admite-se, porém, que a opção de repartição das férias possa ser igualmente influenciada.

Numa perspectiva de análise mais ampliada destaca-se outro fator, relacionado com a massificação do turismo, que resulta da preferência ou motivação evidenciada por alguns segmentos turísticos para este tipo de turismo. Trata-se do consumo num período em que o ambiente na área de destino é humanamente mais denso, agitado e socialmente mais ativo, como é o caso das áreas litorâneas nos meses de verão. No entanto, nem todos os turistas têm as mesmas preferências quanto a isso. À medida que o turismo de massa se desenvolve, registra-se em paralelo, sobretudo no ocidente, uma tendência para o individualismo no consumo turístico, quando as pessoas procuram por viagens diferentes, roteiros e atividades alternativas.

Conclui-se, através desta vertente de análise, que os diversos tipos de motivações dos turistas também são uma explicação essencial para a concentração das férias em determinado período, logo, para a explicação da sazonalidade.

\section{GUARATUBA - SITUAÇÃO GEOGRÁFICA}

O município de Guaratuba localiza-se na porção sul do litoral paranaense (FIGURA 1), contido na folha cartográfica Guaratuba MI - 2858-4, coordenadas no sistema de projeção UTM - 680.000, 740.000 e 7.120.000, 7.170.000 (CONSELHO DO LITORAL, 2002). Segundo dados obtidos a partir de Guaratuba, Prefeitura Municipal (2009), o município está localizado a $3 \mathrm{~m}$ de altitude, possui área de $1.316,51 \mathrm{~km}^{2}$ e dista $115 \mathrm{~km}$ de Curitiba, capital do estado do Paraná, $65 \mathrm{~km}$ de Joinville, em Santa Catarina, e $54 \mathrm{~km}$ da cidade de Paranaguá. Possui população estimada para 2009 em 30.806 habitantes, de acordo com informação do Instituto Brasileiro de Geografia e Estatística, sendo $86 \%$ na área urbana e 14\% na área rural (IBGE, 2000). Seu clima é tropical super-úmido, sem estação seca definida, com temperatura média de $22^{\circ} \mathrm{C}$ no verão e $18^{\circ} \mathrm{C}$ no inverno, e sua latitude é $25^{\circ} 52^{\prime} 58^{\prime \prime}$ Sul e sua longitude é $48^{\circ} 34^{\prime} 29^{\prime \prime}$ Oeste (IPARDES, 2009). Na figura 1 identifica-se 
que se limita ao norte com os municípios de Morretes e Paranaguá e à leste com o município de Matinhos e o Oceano Atlântico. Além destes, Guaratuba também faz divisa com os municípios de Itapoá e Garuva no estado de Santa Catarina e com o município de São José dos Pinhais à oeste.

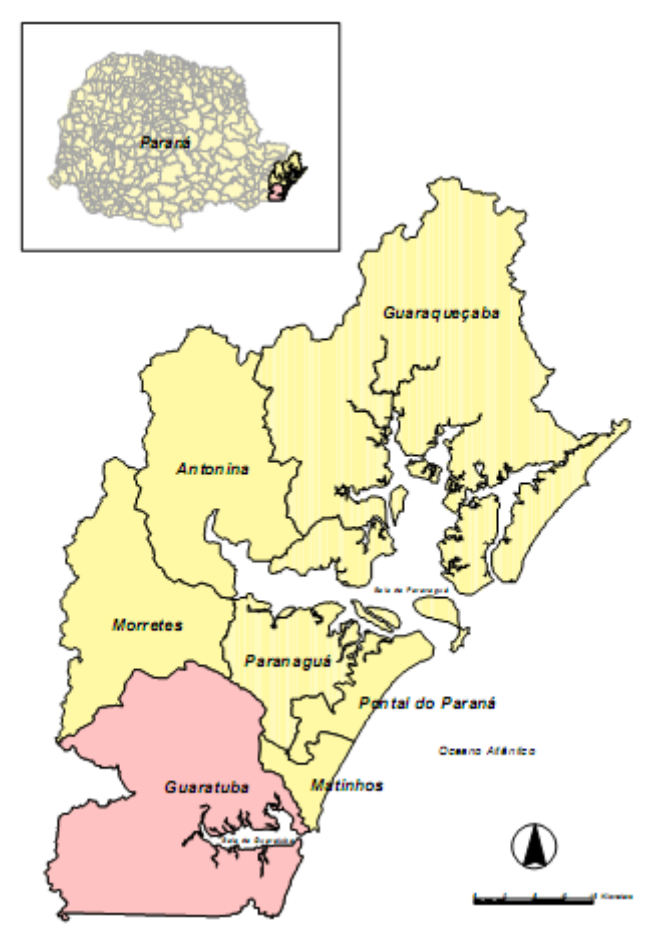

FIGURA 1 - CARTOGRAMA DE LOCALIZAÇÃO DO MUNICÍPIO NO ESTADO DO PARANÁ FONTE: CONSELHO DO LITORAL (2002, p.18).

\section{TURISMO E LAZER EM GUARATUBA}

Guaratuba possui um grande potencial turístico. Suas paisagens e ecossistemas de relevante biodiversidade são considerados pela legislação em vigor como especiais para fins de proteção. (CONSELHO DO LITORAL, 2002). O oceano, as faixas de praia, a baía, seu complexo estuariano, as serras, os morros e a vegetação densa e diversificada compõem um cenário de beleza cênica expressiva, e ao mesmo tempo indica um território, que é principalmente utilizado para o turismo $e$ às atividades a ele vinculadas.

Guaratuba possui uma grande APA (Área de Proteção Ambiental) em meio a Mata Atlântica, mantendo preservadas algumas áreas de restinga na beira da praia, que além de abrigar espécies vegetais típicas, servem de berçário para alguns animais como a coruja buraqueira (CONSELHO DO LITORAL, 2002). 
Em Guaratuba o turismo de massa tem como principal atividade o lazer e a recreação nos seus $15 \mathrm{~km}$ de praia, ou seja, o "turismo de sol e praia" que se estende desde a localidade de Caieiras até a Barra do Saí, inclui-se ainda a Prainha, balneário situado ao norte da baía de Guaratuba (SCHEUER, 2010). Com faixas que variam de 6 a 280 metros de largura, são as praias os maiores atrativos do turismo e geração de atividade econômica na temporada de verão no município (CONSELHO DO LITORAL, 2002). Guaratuba apresenta ainda uma diversidade de ambientes cujo potencial turístico é de grande valor, ressaltando-se por seu grau de importância o complexo estuariano da baía, e em especial, o Rio Boguaçu e seus afluentes. São expressivos o rio Saí-Guaçu, rio São João e a lagoa do Parado (CONSELHO DO LITORAL, 2002).

Quanto aos atrativos turísticos em geral, Guaratuba é uma cidade com muitas praias, eventos locais, lugares religiosos, rios, quedas d'água, turismo náutico, ecológico e até mesmo radical.

\section{PROCEDIMENTOS METODOLÓGICOS}

$\mathrm{Na}$ construção e elaboração da pesquisa trabalhou-se com duas dimensões interligadas, como abordadas por Severino (1996), a dimensão técnica, que trata das regras científicas definindo um objeto, como abordá-lo e como escolher os instrumentos mais adequados para a investigação e a dimensão ideológica relacionada com as escolhas de um pesquisador sobre um tema, o que pesquisar, qual base teórica utilizar e como pesquisar. Destaca-se, portanto que é relevante a opção pessoal de um pesquisador, e por mais que se busque a imparcialidade nas pesquisas, acredita-se que o conhecimento científico é sempre cultural e socialmente condicionado ao momento histórico de quem empreende a observação. A partir dos comentários de Severino (1996), delimitou-se que o objeto de pesquisa deste trabalho seria a sazonalidade do turismo no município de Guaratuba e todas as questões a ela relacionadas.

O desenvolvimento da atividade turística em Guaratuba encontra-se de forma consolidada, atraindo um grande número de turistas, principalmente nos meses em que ocorrem as férias de verão. Mas e nos outros meses do ano, como se comportariam as atividades turísticas e demais atividades econômicas do município? 
A sazonalidade do turismo em Guaratuba acarretaria reflexos tanto na qualidade da prestação de serviços turísticos quanto na vida da comunidade em geral? A partir dos problemas acima enunciados, e da necessidade em estudar o turismo sazonal no município de Guaratuba foram formuladas as seguintes hipóteses transformadas em novos questionamentos: será que ocorreria sazonalidade pela falta de planejamento turístico ou por causa dos fatores climáticos e territoriais? Será que ocorreria sazonalidade pela falta de empenho do empresariado em criar motivos (eventos, programações, novos atrativos) ou pela falta de infraestrutura? Ou ainda, será que a sazonalidade provocaria queda na renda da população acarretando problemas econômicos e sociais?

O objetivo central deste estudo foi estabelecido com a intenção de analisar o turismo sazonal de Guaratuba e seus reflexos na comunidade local, podendo-se assim, caracterizar e comprovar a existência da sazonalidade. Sendo os objetivos específicos: pesquisar dados bibliográficos e documentais sobre o tema proposto; analisar geográfica e turisticamente o município em questão para a sua caracterização e; realizar pesquisa de campo para caracterizar e comprovar a existência da sazonalidade em Guaratuba.

Em relação aos objetivos, esta pesquisa pode ser considerada exploratória e descritiva, pois segundo Gil (2008), as pesquisas exploratórias têm como principal finalidade desenvolver, esclarecer e modificar conceitos e ideias, tendo em vista a formulação de problemas mais precisos e hipóteses pesquisáveis para estudos posteriores. De todos os tipos de pesquisa, estas são as que apresentam menor rigidez no planejamento. Habitualmente envolvem levantamento bibliográfico e documental, entrevistas não padronizadas e estudos de caso. Procedimentos de amostragem e técnicas quantitativas de coleta de dados não são costumeiramente aplicados nestas pesquisas.

A pesquisa foi realizada por meio de levantamento bibliográfico e documental e observação direta intensiva, que conforme Marconi e Lakatos (2008, p. 75), é realizada por meio de duas técnicas: observação e entrevista. Na sua parte empírica, a presente pesquisa se caracteriza como Observação Direta Intensiva, por meio de uso das duas técnicas mencionadas. O tipo de observação utilizado foi a de observação assistemática, ou seja, conforme Marconi e Lakatos (2008) também chamada de não estruturada, espontânea, informal, simples, livre, ocasional, que 
consiste em recolher e registrar os fatos de uma realidade sem que o pesquisador utilize meios técnicos especiais ou precise fazer perguntas diretas. O tipo de amostragem escolhida foi a não probabilística intencional, que segundo as mesmas autoras, é o tipo mais comum de amostra não probabilística, e nela o pesquisador está interessado na opinião de determinados elementos da população.

Seria, por exemplo, o caso de se desejar saber como pensam os líderes de opinião de determinada comunidade. $O$ pesquisador não se dirige, portanto, à "massa", ou seja, a uma população em geral, mas aqueles que segundo seu entender, pela função desempenhada, cargo ocupado, prestígio social, exercem os papéis de líderes de opinião. (MARCONI; LAKATOS, 2008, p. 38).

No caso desta pesquisa, intencionou-se inicialmente que a amostra seria composta de 30 pessoas envolvidas direta ou indiretamente com o turismo local. Das 30 pessoas contatadas, apenas 11 se dispuseram a responder a entrevista.

Também foram realizadas observações sobre o comportamento dos turistas em alta e baixa temporada, bem como, dos impactos ambientais causados pelo turismo de massa na época de veraneio, feriados e finais de semana.

Com relação às entrevistas, foram então questionados 11 (onze) indivíduos: (um do comércio alimentício; um do comércio em geral; um turista de segunda residência; um turista de veraneio; um morador nativo; um da Prefeitura (administrativo); um da Secretaria de Bem Estar Social, Trabalho e Cidadania; um do Departamento de Turismo; um do Departamento de Meio Ambiente; um da Delegacia da Polícia Civil e um da Agência do Trabalhador). A escolha desses indivíduos se deu pelo nível de interferência que exerciam no turismo do município.

Ao iniciar a entrevista, era feita uma breve explicação sobre sua intenção e sobre o significado do termo sazonalidade, depois foram feitas as seguintes perguntas, para posterior análise: Você acha que existe sazonalidade do turismo em Guaratuba? Se sua resposta for sim, de que forma ela afeta o seu negócio e/ou função? Em sua opinião, quais seriam as causas que levam a existência da sazonalidade no município de Guaratuba? Quais os efeitos da sazonalidade em Guaratuba? As entrevistas e observações foram realizadas entre setembro de 2009 e março de 2010. Estas perguntas foram escolhidas com o intuito de comprovar a existência da sazonalidade no município de Guaratuba e os seus reflexos nos entrevistados. 
Por fim, fez-se a interpretação e análise das respostas obtidas para que a sazonalidade do turismo pudesse ser caracterizada e comprovada no município.

\section{PESQUISA DE CAMPO}

A ideia inicial, conforme mencionado anteriormente era a de entrevistar 30 pessoas, que foram contatadas preliminarmente para tal questionamento, dessas apenas 11 aceitaram responder sobre o assunto. Também foi utilizada a observação assistemática, onde foram analisados fatores ligados diretamente às causas e efeitos da sazonalidade. Os resultados da pesquisa foram expostos num quadro composto pelas principais causas e efeitos identificados pelos entrevistados e a posterior análise dos resultados (QUADRO 2). A observação foi dividida em sazonalidade natural e sazonalidade institucional para melhor compreensão, e sequencialmente as considerações também constam na análise dos resultados.

\section{ENTREVISTA FOCALIZADA}

A entrevista focalizada é considerada livre e conforme Gil (2008) enfoca um tema bem específico, neste caso, a sazonalidade. $O$ autor argumenta que 0 entrevistado deve falar livremente sobre o assunto, mas quando ele se desviar do tema original, o entrevistador deve esforçar-se para a sua retomada.

Ao iniciar a entrevista focalizada, foram feitas colocações sobre o tema (causas e efeitos da sazonalidade), para que as pessoas compreendessem melhor o assunto. Após as devidas explicações as perguntas eram feitas e as pessoas tinham que simplesmente falar. Como resultado final de toda a investigação pode-se elaborar uma ilustração específica (FIGURA 2) sobre as causas e efeitos da sazonalidade do turismo em Guaratuba.

\section{OBSERVAÇÃO ASSISTEMÁTICA}

Para elaborar a observação assistemática, que conforme Marconi e Lakatos (2008) é uma técnica não estruturada, também podendo ser denominada de espontânea, simples e livre, que consiste em recolher e registrar os fatos da 
realidade sem que o pesquisador utilize meios técnicos específicos ou precise fazer perguntas diretas levou-se em consideração as categorias de causas da sazonalidade conforme Hartmann (1986) apud Köenig-Lewis e Bischoff $(2005)^{3}$ que subdivide a sazonalidade em natural e institucional.

\section{SAZONALIDADE NATURAL EM GUARATUBA}

Como comentado anteriormente, a sazonalidade natural engloba vários fatores ligados diretamente com a variação do clima. No que se refere ao clima, Guaratuba é ainda muito dependente do sol e do calor, como cidade balneária e sem praticamente opções de lazer e de infraestrutura fora da temporada de verão, sofre com o desequilíbrio sazonal da procura, que está ligado não apenas ao tipo de procura, mas também ao da oferta existente.

Os turistas visitam o município principalmente por causa da praia e do calor, não se importando com os preços ou com grandes engarrafamentos, o que querem na verdade é usufruir da oferta que o município oferece nesta época do ano. Já em outras épocas, caracterizada como baixa temporada, o turista, geralmente de segunda residência procura o município aos finais de semana para descansar e buscar um clima mais ameno, já que, mesmo no inverno, Guaratuba possui um clima agradável.

O turismo de massa que acontece na alta temporada traz consigo grandes impactos no meio ambiente, pois ocasiona sujeira das ruas e praias, poluição de rios, do mar e da baía (através dos esgotos que são jogados diretamente no oceano), degradação de áreas de preservação, como é o caso das áreas de restinga e dos mangues.

O que se observa é que enquanto Guaratuba não oferecer opções de lazer que não dependam essencialmente do sol e da praia, o cenário não mudará. Os moradores já estão condicionados a trabalhar bastante no verão e trabalhar menos ou quase nada no inverno, dessa forma, o município, fica à mercê do funcionalismo público e da baixa qualidade dos serviços prestados durante grande parte do ano.

\footnotetext{
${ }^{3}$ HARTMANN, R. Tourism, Seasonality and Social Change. Leisure Studies. 5 (1): p. 25-33, 1986.
} 


\section{SAZONALIDADE INSTITUCIONAL EM GUARATUBA}

A sazonalidade institucional está intimamente ligada aos fatores socioeconômicos e socioculturais, ou seja, dependente das férias escolares, das férias profissionais, dos feriados, e dos calendários nacional, estadual e municipal de eventos e também de questões de renda.

Além do clima, a sazonalidade institucional também é bem caracterizada em Guaratuba, já que praticamente não possui atrativos diferenciados para outras épocas, que não seja a do verão. As pessoas estão condicionadas a viajar para Guaratuba em período de férias escolares e profissionais, ou seja, geralmente durante os meses de verão (dezembro a março) ou durante as férias escolares de inverno (julho) em menor escala. O que se percebe é que no inverno, a maioria dos visitantes são os moradores de segunda residência que visitam o município com o intuito de passar alguns dias, ou finais de semana em suas moradias. Um fator importante que traz essas pessoas no inverno é a Festa do Divino (10 dias de festa religiosa), que ocorre no mês de julho (GUARATUBA, 2009) movimentando o município durante esse período.

Durante o verão, os governantes do município de Guaratuba em parceria com os do Governo do Estado e empresários locais oferecem uma diversificação de atividades de lazer, esportivas e culturais, atividades essas, que em outras épocas do ano não acontecem, pois o município não possui verbas para tais investimentos, - Governo do Estado retira sua "Operação Verão" e a maioria dos empresários fecham suas portas para não correrem o risco da falência por falta de demanda. Com isso, enquanto não houver opções diferenciadas de atividades e/ou eventos em diferentes épocas do ano, Guaratuba permanecerá dependente do turismo de "sol e praia".

Guaratuba não precisaria perder sua identidade de município balneário, onde as praias e o lazer ao sol são de grande relevância, mas poderia oportunizar opções diferenciadas de turismo durante várias épocas do ano, já que é um município com ampla extensão territorial, com áreas de proteção ambiental e envolvimento com o turismo cultural, de eventos, o ecoturismo, o turismo náutico e o turismo rural. Sua vocação primordial é para turismo de "sol e praia", mas sua infraestrutura e 
equipamentos poderiam ser utilizados para que outras vertentes do turismo fossem trabalhadas em outros períodos do ano.

\section{ANÁLISE DOS RESULTADOS}

Para melhor visualização dos dados coletados e posterior cruzamento e análise dos mesmos, foi elaborado um resumo (QUADRO 2), onde são demonstradas as respostas dos entrevistados na pesquisa de campo (entrevista focalizada). Na primeira coluna do quadro foi colocado quem foi o entrevistado e na segunda, como essa pessoa era afetada pela sazonalidade. Na terceira coluna foram colocadas as causas da sazonalidade, segundo o entrevistado, e na última lacuna, quais os efeitos da sazonalidade conforme a opinião do entrevistado.

QUADRO 2. CAUSAS E EFEITOS DA SAZONALIDADE NO MUNICÍPIO DE GUARATUBA SOB ÓTICA DOS ENTREVISTADOS

\begin{tabular}{|c|c|c|c|}
\hline ENTREVISTADO & $\begin{array}{c}\text { COMO É AFETADO } \\
\text { PELA } \\
\text { SAZONALIDADE }\end{array}$ & CAUSAS & EFEITOS \\
\hline $\begin{array}{l}\text { Proprietário de } \\
\text { Restaurante - } \\
\text { Churrascaria (aberto o } \\
\text { ano todo) }\end{array}$ & $\begin{array}{l}\text { * Precisa de muita } \\
\text { mão-de-obra na } \\
\text { temporada e fora da } \\
\text { temporada os seus } \\
\text { profissionais ficam } \\
\text { ociosos; } \\
\text { * Trabalha com déficit } \\
\text { durante } 6 \text { meses no } \\
\text { ano; } \\
\text { * Falta de mão-de-obra } \\
\text { qualificada. }\end{array}$ & $\begin{array}{l}\text { * Férias escolares e } \\
\text { feriados; } \\
\text { * Falta do que fazer } \\
\text { fora da temporada; } \\
\text { * Comércio } \\
\text { praticamente fechado } \\
\text { e sem qualidade; } \\
\text { * Falta de } \\
\text { infraestrutura de } \\
\text { saúde; } \\
{ }^{*} \text { Clima. }\end{array}$ & $\begin{array}{l}\text { * Desemprego; } \\
\text { * Falta de dinheiro na } \\
\text { economia local; } \\
\text { * Aumento da } \\
\text { criminalidade; } \\
\text { * Preços altos no } \\
\text { verão; } \\
\text { * Lixo e sujeira na } \\
\text { temporada. }\end{array}$ \\
\hline $\begin{array}{l}\text { Proprietária de uma } \\
\text { Loja de Roupas } \\
\text { (localizada no Centro } \\
\text { de Guaratuba) }\end{array}$ & $\begin{array}{l}\text { * Número de } \\
\text { funcionárias aumenta } \\
\text { muito na temporada de } \\
1 \text { (fora de temporada } \\
\text { para } 5 \text { (na temporada); } \\
\text { * Alto giro de dinheiro } \\
\text { no verão e quase nada } \\
\text { no inverno; } \\
\text { * Trabalha com déficit } \\
\text { durante boa parte do } \\
\text { ano (estoque parado). }\end{array}$ & $\begin{array}{l}\text { * Clima; } \\
\text { * Período de férias } \\
\text { (verão e inverno); } \\
\text { * Turistas de segunda } \\
\text { residência não têm } \\
\text { opções de lazer; } \\
\text { * Falta Marketing } \\
\text { Turístico. }\end{array}$ & $\begin{array}{l}\text { * População com baixa } \\
\text { renda no período de } \\
\text { inverno; } \\
\text { * Preços abusivos na } \\
\text { temporada; } \\
\text { * Aumento da } \\
\text { criminalidade; } \\
\text { * A população local } \\
\text { perde a identidade. }\end{array}$ \\
\hline $\begin{array}{l}\text { Turista de Segunda } \\
\text { Residência }\end{array}$ & $\begin{array}{l}\text { * Preços altos na } \\
\text { temporada; } \\
\text { * Trânsito igual ao dos } \\
\text { grandes centros; } \\
\text { * Fila para tudo; } \\
\text { * Poluição ambiental, } \\
\text { sonora e visual. }\end{array}$ & $\begin{array}{l}\text { * Falta de } \\
\text { infraestrutura de saúde } \\
\text { e de lazer fora de } \\
\text { temporada; } \\
\text { * Clima; } \\
\text { * Período de férias; } \\
\text { * Renda extra no final } \\
\text { do ano. }\end{array}$ & $\begin{array}{l}\text { * Desemprego; } \\
\text { * Pobreza no inverno; } \\
\text { * Preços altos na } \\
\text { temporada. }\end{array}$ \\
\hline
\end{tabular}




\begin{tabular}{|c|c|c|c|}
\hline Turista de Veraneio & * Preços altos. & $\begin{array}{l}\text { * Clima; } \\
\text { * Período de férias; } \\
\text { * Distância. }\end{array}$ & $\begin{array}{l}\text { * Desemprego; } \\
\text { * Pouco giro de } \\
\text { dinheiro fora da } \\
\text { temporada; } \\
\text { * Preços altos. }\end{array}$ \\
\hline $\begin{array}{l}\text { Morador Local - } \\
\text { Pescador }\end{array}$ & $\begin{array}{l}\text { * Mais renda no verão; } \\
\text { * Resto do ano fica } \\
\text { praticamente sem } \\
\text { renda; } \\
\text { * Falta trabalho no } \\
\text { inverno. }\end{array}$ & $\begin{array}{l}\text { * Clima; } \\
\text { * Férias; } \\
\text { * Falta do que fazer. }\end{array}$ & $\begin{array}{l}\text { * Desemprego; } \\
\text { * Falta de renda; } \\
\text { * Aumento da } \\
\text { criminalidade. }\end{array}$ \\
\hline $\begin{array}{l}\text { Prefeitura - } \\
\text { Funcionário } \\
\text { Administrativo }\end{array}$ & $\begin{array}{l}\text { * Planejamento } \\
\text { administrativo e } \\
\text { urbano; } \\
\text { * A estrutura de } \\
\text { abastecimento e de } \\
\text { saúde; } \\
\text { * Mais pessoas para } \\
\text { trabalhar na prefeitura } \\
\text { no verão; } \\
\text { * Dificuldade em } \\
\text { atender as prioridades } \\
\text { dos moradores fixos no } \\
\text { verão. }\end{array}$ & $\begin{array}{l}\text { * Clima; } \\
\text { * Período de férias; } \\
\text { * Falta de eventos, } \\
\text { festas, congressos; } \\
\text { * Falta de estrutura } \\
\text { médico hospitalar; } \\
\text { * Falta de um plano de } \\
\text { marketing turístico. }\end{array}$ & $\begin{array}{l}\text { * Desemprego; } \\
\text { * Aumento da } \\
\text { criminalidade; } \\
\text { * População local com } \\
\text { baixa renda; } \\
\text { * Lixo; } \\
\text { * Degradação do meio } \\
\text { ambiente natural e } \\
\text { urbano. }\end{array}$ \\
\hline $\begin{array}{l}\text { Secretaria do Bem } \\
\text { Estar Social, Trabalho } \\
\text { e Cidadania }\end{array}$ & $\begin{array}{l}\text { * Problemas sociais no } \\
\text { verão com mendigos e } \\
\text { pedintes e no inverno } \\
\text { com pessoas ociosas e } \\
\text { endividadas; } \\
{ }^{*} \text { Necessidade de } \\
\text { prestar assistência a } \\
\text { esses dois públicos em } \\
\text { épocas distintas e com } \\
\text { soluções diferentes. }\end{array}$ & $\begin{array}{l}\text { * Férias; } \\
\text { * Clima; } \\
{ }^{*} \text { Falta de atividades } \\
\text { no inverno. }\end{array}$ & $\begin{array}{l}\text { * Baixa autoestima da } \\
\text { população em } \\
\text { períodos de baixa } \\
\text { estação; } \\
\text { *Aumento da } \\
\text { criminalidade; } \\
\text { * Desemprego. }\end{array}$ \\
\hline $\begin{array}{l}\text { Departamento de } \\
\text { Turismo }\end{array}$ & $\begin{array}{l}\text { * Mais trabalho; } \\
{ }^{*} \text { Percebeu que a } \\
\text { temporada de verão } \\
\text { diminuiu de } 3 \text { para } 2 \\
\text { meses. }\end{array}$ & $\begin{array}{l}\text { * Falta infraestrutura } \\
\text { geral e de apoio ao } \\
\text { turismo; } \\
\text { * Falta qualificação da } \\
\text { mão-de-obra; } \\
\text { * Idéia de cidade } \\
\text { pequena e atrasada; } \\
\text { * Falta de atividades } \\
\text { de lazer; } \\
\text { * Falta de } \\
\text { infraestrutura } \\
\text { adequada para } \\
\text { eventos; } \\
\text { * Pouco turismo } \\
\text { náutico e ecoturismo, } \\
\text { * Pouca segurança; } \\
\text { * Pouca infraestrutura } \\
\text { de saúde; } \\
\text { * Falta de um plano } \\
\text { diretor de } \\
\text { desenvolvimento } \\
\text { econômico e turístico. }\end{array}$ & $\begin{array}{l}\text { * Trabalhos } \\
\text { esporádicos; } \\
\text { * Desemprego; } \\
\text { * Falta de estoques } \\
\text { reguladores em } \\
\text { supermercados; } \\
\text { * Pouca capacidade de } \\
\text { carga no trânsito; } \\
\text { * Preços altos; } \\
\text { * Falta de mão-de-obra } \\
\text { qualificada na } \\
\text { temporada; } \\
\text { * Ociosidade dos } \\
\text { serviços fora de } \\
\text { temporada. }\end{array}$ \\
\hline $\begin{array}{l}\text { Departamento de Meio } \\
\text { Ambiente }\end{array}$ & $\begin{array}{l}{ }^{*} \text { Na temporada de } \\
\text { verão trabalha mais } \\
\text { com o turista; } \\
{ }^{*} \text { No inverno trabalha }\end{array}$ & $\begin{array}{l}\text { " Clima; } \\
\text { " Férias; } \\
\text { " Falta de atividades } \\
\text { fora da temporada de }\end{array}$ & $\begin{array}{l}\text { * Desemprego; } \\
\text { * Falta de mão-de-obra } \\
\text { qualificada. }\end{array}$ \\
\hline
\end{tabular}




\begin{tabular}{|c|c|c|c|}
\hline & $\begin{array}{l}\text { mais com projetos } \\
\text { sustentáveis com a } \\
\text { população local. }\end{array}$ & verão. & \\
\hline $\begin{array}{l}\text { Polícia Civil de } \\
\text { Guaratuba }\end{array}$ & $\begin{array}{l}\text { * Trabalha menos no } \\
\text { verão, por causa da } \\
\text { Operação Verão do } \\
\text { Governo do Estado; } \\
\text { * Problemas com } \\
\text { inquéritos abertos na } \\
\text { temporada de verão; } \\
\text { * Fora de temporada } \\
\text { sofrem com tráfico de } \\
\text { drogas, os } \\
\text { arrombamentos e com } \\
\text { os homicídios. }\end{array}$ & $\begin{array}{l}\text { * Clima; } \\
\text { * Férias; } \\
\text { * Falta de opções de } \\
\text { lazer fora da } \\
\text { temporada de verão. }\end{array}$ & $\begin{array}{l}\text { * Aumento da } \\
\text { criminalidade; } \\
\text { * Desemprego. }\end{array}$ \\
\hline $\begin{array}{l}\text { Agência do } \\
\text { Trabalhador de } \\
\text { Guaratuba }\end{array}$ & $\begin{array}{l}\text { * Serviço bem sazonal, } \\
\text { épocas com muito } \\
\text { trabalho e épocas } \\
\text { ociosas. }\end{array}$ & $\begin{array}{l}\text { * Clima; } \\
\text { * Férias; } \\
\text { * Falta de atividades } \\
\text { fora de temporada de } \\
\text { verão; } \\
\text { * Falta de Marketing } \\
\text { Turístico. }\end{array}$ & $\begin{array}{l}\text { * Desemprego; } \\
\text { * Aumento da } \\
\text { criminalidade; } \\
\text { * Falta de dinheiro no } \\
\text { comércio; } \\
\text { * Endividamento da } \\
\text { população local. }\end{array}$ \\
\hline
\end{tabular}

FONTE: SCHEUER, 2010.

Analisando os dados obtidos através da observação e por entrevista focalizada, pode-se caracterizar a sazonalidade do turismo no município de Guaratuba. Além desses dados coletados, dados fornecidos por Guaratuba (2009) como, por exemplo, o número de população flutuante e estudo de demanda da Secretaria de Estado do Turismo (SETU - PR, 2008) foram essenciais para esta análise.

Por meio da entrevista focalizada e da observação assistemática conseguiuse caracterizar, as causas e efeitos da sazonalidade. A partir daí, conciliando tais resultados com o referencial teórico exposto ao longo deste trabalho e de aspectos vivenciados no cotidiano da cidade, teve-se como elaborar a figura 2 , baseando-se em Mota (2001), em que resumidamente tem-se como visualizar e apresentar as causas e os efeitos da sazonalidade do município de Guaratuba. 


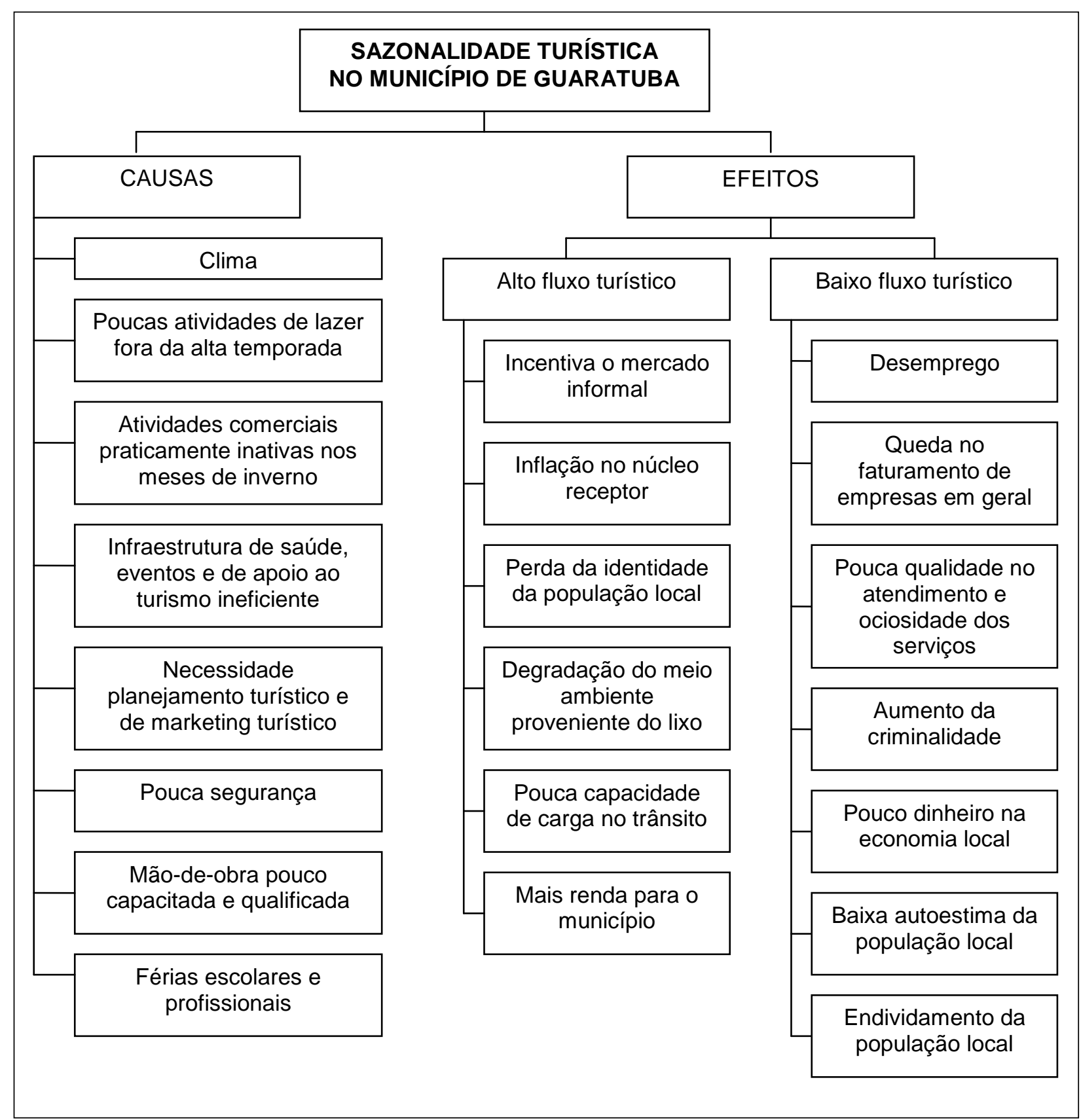

FIGURA 2. CAUSAS E EFEITOS DA SAZONALIDADE DO TURISMO NO MUNICÍPIO DE GUARATUBA

FONTE: SCHEUER, 2010. Adaptado de MOTA, K. C. N., 2001.

A partir da figura 2, pode-se constatar que Guaratuba se caracteriza como uma cidade sazonal, com suas peculiaridades em relação ao turismo e que ainda depende essencialmente do turismo de "sol e praia" e que sofre com as causas e os efeitos advindos da sazonalidade, já que o número de efeitos negativos mencionados superou os positivos.

Neste estudo buscou-se levantar as causas e os efeitos da sazonalidade no município de Guaratuba especificamente, chegando-se a conclusão que as 
principais causas da sazonalidade no município são: o clima; a falta de atividades de lazer fora da alta temporada; atividades comerciais praticamente inativas no inverno; infraestrutura para saúde, para eventos e de apoio ao turismo ineficientes; falta de um plano de marketing turístico; mão-de-obra pouco capacitada e qualificada; pouca segurança e as férias escolares e profissionais. Quando questionados, a maioria dos entrevistados citou que o clima e as férias eram os maiores causadores da sazonalidade, mas ao se refletir sobre tais aspectos chegou-se à conclusão de que a cidade poderia reverter esse problema se proporcionasse ao visitante de fora de temporada de verão mais estrutura de saúde, para eventos e qualidade nos serviços prestados, atraindo mais visitantes em outras épocas do ano.

Quanto aos efeitos, com o alto fluxo de pessoas é perceptível que há um incentivo ao mercado informal, que os preços sofrem uma grande alta, que a população local perde parte de sua identidade, já que procura acompanhar a cultura do visitante. Já o meio ambiente é mais degradado pela quantidade de pessoas que o usufrui e o trânsito que não comporta a grande quantidade de automóveis. $O$ aspecto positivo de tudo isso, é que o município arrecada mais e os munícipes nessa época conseguem uma renda extra. Já quando há baixo fluxo de pessoas, e isso acontece na maior parte do ano, os efeitos são mais drásticos, pois há um grande aumento no número de desempregados; o faturamento das empresas cai bruscamente; há queda na qualidade dos serviços prestados e ociosidade; aumenta a criminalidade, devido à escassez de empregos e de renda. Nessa época, as pessoas veem sua autoestima cair e o endividamento da população é uma das consequências.

Guaratuba precisa se inserir dentro do contexto de um planejamento turístico de médio e de longo prazo, com estratégias para que seu território seja utilizado de maneira coerente por munícipes e pela demanda esperada de pessoas tanto, na alta temporada (verão) como em outras épocas do ano, procurando formas de atrair pessoas que possam usufruir o que o município tem a oferecer.

\section{CONCLUSÃO}

Este estudo buscou demonstrar a existência de um consenso relativo à complexidade que caracteriza a sazonalidade do turismo, não tanto no que se refere 
às suas consequências, mas particularmente quanto às suas causas, tendo o município de Guaratuba como estudo de caso.

As cidades com seus serviços e equipamentos, são lugares em que os elementos naturais e culturais estão inseridos e distribuídos de forma diferenciada, conferindo ao turismo uma dimensão espacial. Esses lugares são habitados e os habitantes, portanto, são os anfitriões. O turismo é uma atividade que implica o consumo de espaços com diversidade de formas de utilização e dá agilidade a processos dotados de grande capacidade de organização territorial. Cada modalidade de turismo cria uma demanda por um determinado tipo de espaço, quer sejam áreas de montanha, de litoral, urbanas ou rurais.

Neste ínterim, Guaratuba é um município caracterizado pelo turismo de "sol e praia" e nitidamente volúvel à renda advinda da alta temporada (verão), o que causa grandes impactos sociais e econômicos durante outros períodos do ano. Guaratuba, se bem planejada turisticamente, poderia tornar-se um polo do turismo paranaense durante todos os meses do ano, procurando agregar outros tipos de turismo (eventos, esportivo, ecológico, entre outros) ao já existente (sol e praia), explorando de forma adequada o seu patrimônio cultural, histórico e natural. Dessa forma valorizando o que a cidade tem a oferecer de melhor e consequentemente trabalhando novas atividades geradoras de emprego e renda.

Este estudo também se propôs a comprovar e caracterizar a sazonalidade, ou seja, épocas de grande demanda por espaço, lazer e infraestrutura e épocas com pouca ou nenhuma demanda, no município de Guaratuba constatada através de pesquisa focalizada com 11 indivíduos ligados direta ou indiretamente com 0 turismo. O problema da pesquisa questionava se a sazonalidade do turismo em Guaratuba acarretava reflexos tanto na qualidade de prestação de serviços turísticos quanto na vida da comunidade em geral. Pode-se concluir que no município identificou-se haver baixa qualidade da prestação de serviços em todas as épocas do ano, e que a comunidade local é a que mais está relacionada aos efeitos negativos da sazonalidade, pois fica sem qualificação, sem emprego, amargando problemas de endividamento e de criminalidade.

Ao se analisar os resultados da pesquisa, se pôde comprovar não haver a plenitude de um planejamento específico para o turismo e que os fatores climáticos são a principal motivação e causa da sazonalidade do município, já que todos os 
entrevistados responderam ser o clima o principal fator que ocasiona a sazonalidade. Sobre o fator relacionado aos motivos de ocorrência da sazonalidade, constatou-se realmente faltar atividades complementares às naturais, como por exemplo: eventos, lazer e programações motivadoras para que as pessoas visitem o município em outras ocasiões, que não seja a da temporada de verão. Sobre os problemas socioeconômicos advindos da sazonalidade, considera-se que foram os que ficaram mais evidenciados na pesquisa de campo, pois em Guaratuba os moradores apresentam diversas desvantagens competitivas, como despreparo e baixo poder aquisitivo, principalmente fora da temporada de verão. Tais constatações reforçaram a comprovação da necessidade de um planejamento mais amplo do turismo, integrando o setor público com o privado.

Para que os efeitos negativos da sazonalidade pudessem ser ao menos minimizados, seria necessária maior interação na relação público-privada, em que todos os atores envolvidos pudessem contribuir para com o desenvolvimento turístico do município, embasados em legislação de gestão ambiental costeira existente, e que os atores locais, os principais impulsionadores da aplicação de programas de gestão integrada pudessem garantir um desenvolvimento mais estável de regiões litorâneas, como Guaratuba.

Neste contexto, verificou-se que a investigação foi comprovada, através da pesquisa de campo, em que ficou caracterizada e evidenciada a existência da sazonalidade, suas causas e efeitos do município em questão. Neste estudo também se conseguiu constatar a existência do turismo de segunda residência no município, característica de muitas cidades litorâneas. Por fim, julga-se pertinente comentar que este trabalho foi um estudo preliminar sobre a existência da sazonalidade no município de Guaratuba, que poderá futuramente desencadear outros de caráter mais qualitativo sobre o significado da sazonalidade sob o ponto de vista do visitante e o impacto das correlações entre diferentes contextos de destino e as experiências, percepções e constrangimentos sazonais dos turistas.

\section{REFERÊNCIAS}

ALMEIDA, E. M. de. Turismo Litorâneo: Ocupação urbana e formação de ilhas de calor. Turismo em Análise. São Paulo: Escola de Comunicação e Artes da USP, v. 11, n. 2, p. 71-89, 2000.

ALMEIDA, A. L. de; KASTENHOLZ E. A sazonalidade no turismo e a estratégia de diversificação da procura: O Caso do Norte de Portugal. Conceptual Paper, $2^{\circ}$ 
Encontro Luso-Brasileiro de Estratégia, ELBE: Lisboa, Portugal 2008. Disponível em: <http://www.atsie.com/Portals/4/artigos/A\%20sazonalidade\%20no\%20Turismo.pdf>. Acesso em: 15/06/2009.

BAHL, M. Agrupamentos Turísticos Municipais. Curitiba: Protexto, 2004.

BARON, R. R. V. Seasonality in Tourism: A guide to analysis of seasonality. Economist Intelligence Unit Technical Paper, London, n. 2, 1975.

BARRETTO, M. Planejamento e Organização do Turismo. 4. ed. Campinas: Papirus, 1991.

BAUM, T.; HAGEN, L. Responses to seasonality: the experiences of peripheral destinations. International Journal of tourism research. v. 1. i.4. Wiley: 299-312, 1999.

BONFIM, B. B. R. A Geografia na Formação do Profissional em Turismo. 2007. 274 f. Tese (Doutorado em Geografia) - Faculdade de Filosofia, Letras, Ciências Humanas, Universidade de São Paulo - USP, São Paulo, 2007.

BONIFACE, B. G.; COOPER, C. The geography of travel \& tourism. Oxford: Butterworth-Heinemann, 1994.

BUTLER, R. Seasonality in tourism: Issues and problems. In: Tourism: The State of the Art. SEATON, A. V. Chichester: Wiley, p. 332-339, 1994.

Seasonality in Tourism: Issues and Implications. In: Seasonality in Tourism. BAUM, T.; LUNDTORP, S. (Org.) Oxford: Pergamont, p. 5-21, 2001.

BUTLER, R.; MAO, B. Seasonality in Tourism: Problems and Measurement. Quality Management in Urban Tourism. P.E. Murphy. Chichester, Wiley: 9-23, 1996.

CONSELHO DO LITORAL. Plano Diretor de Desenvolvimento Integrado Guaratuba (PDDI). Curitiba: Governo do Estado do Paraná, 2002.

CROCIA, N. Análise Regional e Destinações Turísticas: possibilidades teóricas e situações empíricas em geografia do turismo. Turismo - Visão e Ação. v. 4. n. 11, p. $9-28$ 2002. Disponível em: <https://www6.univali.br/seer/index.php/rtva/article/viewFile/1164/920> Acesso em: 10/02/2010.

DENCKER, A. de F. M. Métodos e técnicas de pesquisa em turismo. 3. ed. São Paulo: Futura, 1998.

FRECHTLING, D.C. World Conference on the economic impact of tourism. International Journal of tourism research. v. 3. i.3. Wiley: 253-255, 2001.

GIL, A. C. Métodos e Técnicas de Pesquisa Social. 6. ed. São Paulo: Atlas, 2008.

GUARATUBA, Prefeitura Municipal. 2009. Disponível em: <http://www.guaratuba.pr.gov.br/site/index.php> Acesso em: 12/12/2009.

HARTMANN, R. Tourism, Seasonality and Social Change. Leisure Studies 5: 25-33, 1986.

INSTITUTO BRASILEIRO DE GEOGRAFIA E ESTATÍSTICA - IBGE. Domicílios e população, Censo 2000. Disponível em: <http://www.ibge.gov.br/home/> Acesso em: 15/06/2010. 
INSTITUTO PARANAENSE DE DESENVOLVIMENTO ECONÔMICO E SOCIAL IPARDES. Caderno Estatístico do Município de Guaratuba, 2009. Disponível em: <http://www.ipardes.gov.br/index.php> Acesso em: 10/05/2010.

IVARS, J. A. Planificación turística de los espacios regionales em Espanha. Madri: Síntesis, 2002.

KÖENIG-LEWIS, N; BISCHOFF, E. Seasonality Research: The State of the Art. International Journal of Tourism Research 7, p. 201-219, 2005.

KRIPPENDORF, J. Sociologia do turismo. Para uma nova compreensão do lazer e das viagens. Rio de Janeiro: Civilização Brasileira, 1989.

LAGE, H. G.; MILONE, P. C. Economia do turismo. Campinas: Papirus, 1998. . Impactos socioeconômicos globais do Turismo. In: LAGE, H. G.; MILONE, P. C. (Org). Turismo - teoria e prática. São Paulo: Atlas, 2000, p. 117-13.

MARCONI, M. de A.; LAKATOS, E. M. Técnicas de Pesquisa. 7. ed. São Paulo: Atlas, 2008.

MITCHEL, L.; MURPHY, P. Geography and tourism. Annals of Tourism Research, n. 18, p. 57-70, 1991.

MOTA, K. C. N. Marketing Turístico: promovendo uma atividade sazonal. São Paulo: Atlas, 2001.

ORGANIZAÇÃO MUNDIAL DO TURISMO - OMT. Introdução ao turismo. Trad. Dolores Martin Rodriguez Corner. São Paulo: Roca, 2001.

OSBORNE, D. R. Seasonality and habit persistence in a life cycle model of consumption. Modelling Seasonality. S. Hylleberg. Oxford: Oxford University Press, p. 193-208, 1992.

PARANÁ, Secretaria de Estado do Turismo - SETU-PR. Região Turística: Litoral do Paraná em dados, 2008. Disponível em: <http://www.setu.pr.gov.br> Acesso em: 05/06/2009.

PEARCE, D. Desarrollo Turístico: su planificácion y ubicación geográfica. México: Trillas, 1988.

REJOWSKI, M. Turismo e pesquisa científica: pensamento internacional $X$ situação brasileira. Campinas: Papirus, 1996. (Coleção Turismo).

RUSCHMANN, D. Marketing Turístico: Um enfoque promocional. 2. ed. Campinas: Papirus, 1995.

SCHEUER, L. Plano de Desenvolvimento Turístico do Município de Guaratuba. AMLIPA, 2010.

, L. Sazonalidade do Turismo no Município de Guaratuba - PR. 2010. 189f. Dissertação (Mestrado em Geografia) - Universidade Federal do Paraná UFPR, Curitiba, 2010.

SEVERINO, A. J. Metodologia do trabalho científico. 20. ed. São Paulo: Cortez, 1996. 